\title{
EFFECTS OF LEAD TOXICITY ON GROWTH AND CELL WALL EXTENSIBILITY IN RICE SEEDLINGS
}

\author{
Mohammad Talim Hossain ${ }^{*}$, Kouichi Soga, Kazuyuki WaKabayashi \\ AND TAKAYUKI Hoson
}

Department of Biology, Osaka City University, Osaka 558-8585, Japan

Key words: Cell wall extensibility, Growth, Lead toxicity, Rice seedlings

\begin{abstract}
The effect of lead $(\mathrm{Pb})$ on growth and mechanical properties of cell wall was investigated in rice seedlings. Caryopses of rice were germinated and grown in various concentrations of lead nitrate for 5 days at $25^{\circ} \mathrm{C}$ in the dark. Growth of rice seedlings was suppressed by $\mathrm{Pb}$ ions; significant suppression was caused by low concentration of $\mathrm{Pb}$ as $1 \mu \mathrm{M}$. Growth suppression was prominent in roots, but not clear in shoot organs, such as coleoptiles or first leaves, suggesting that roots are the primary target of Pb toxicity. The analysis of the cell wall extensibility of rice roots grown in $\mathrm{Pb}$ solution indicated that the cell wall extensibility was greatly decreased with increased concentration of $\mathrm{Pb}$ ions. These results suggest that $\mathrm{Pb}$ may influence the synthesis of cell wall polysaccharides, thereby decreasing the cell wall extensibility, resulting in growth suppression in rice roots.
\end{abstract}

Although $\mathrm{Pb}$ is not an essential element for plants, it is easily taken up by plants from the soil and accumulated in different organs. After being taken up by roots, the localization of $\mathrm{Pb}$ is greater in roots than in other parts of the plants (Sharma and Dubey 2005). Pb binds strongly to the carboxyl groups of galacturonic acid and glucuronic acid in the cell wall, which restricts its transportation via apoplast (Rudakova et al. 1988). $\mathrm{Pb}$ decreases seed germination, length and biomass of root and shoot of rice seedlings (Mishra and Choudhuri 1998). Pb toxicity causes serious damage to seedling growth and chlorosis in leaves (Burton et al. 1984, Hossain et al. 2007). However, the mechanisms of growth suppression due to $\mathrm{Pb}$ toxicity are less known in crop plants. The aims of the present study were to analyze the effect of $\mathrm{Pb}$ on growth and mechanical properties of root cell wall in rice seedlings.

Caryopses of rice (Oryza sativa, cv. Koshihikari) were used as experimental plant materials. Caryopses were first surface-sterilized with 5\% sodium hypochlorite solution for $1 \mathrm{hr}$ to avoid fungal infection and then washed several times with running tap water and also with distilled water. After that caryopses were soaked in distilled water for $24 \mathrm{hrs}$ at $25^{\circ} \mathrm{C}$ in the dark and then germinated and grown in different concentrations of $\mathrm{Pb}\left(\mathrm{NO}_{3}\right)_{2}$ up to 5 days at $25^{\circ} \mathrm{C}$ in the dark. Control sample was treated with distilled water. The $\mathrm{pH}$ of the $\mathrm{Pb}$ solution was adjusted to 5.5 using $5 \mathrm{mM}$ MES-KOH buffer solution. Germinated caryopses were cultivated on wet gauze so radicles elongated into each cultural solution. After that 3-, 4- and 5-day-old seedlings were harvested and then lengths and fresh weights of coleoptiles, first leaves and roots were measured.

To determine the mechanical properties of the cell wall, rice roots grown for 3 days were boiled for $10 \mathrm{~min}$ in $80 \%$ ethanol (v/v) and stored in fresh $80 \%$ ethanol as above. The ethanolkilled roots were then rehydrated for $1 \mathrm{hr}$ with several changes of distilled water. Segments of 10 $\mathrm{mm}$ cut from the subapical region of the roots were fixed between two clamps (the distance between the clamps being $2 \mathrm{~mm}$ ) of a tensile teste (Tensilon RTM-25, Toyo Baldwin, Tokyo,

*Author for correspondence: <talim_ju@yahoo.com>. ${ }^{1}$ Present Address: Department of Botany, Jahangirnagar University, Savar, Dhaka-1342, Bangladesh. 
Japan), connected to a personal computer. They were stretched by lowering the bottom clamp at a speed of $20 \mathrm{~mm} / \mathrm{min}$ to produce a stress of $5 \mathrm{~g}$. The magnitude of the stresses was determined to allow the plant specimens adequate extension and stress-relaxation. The cell wall extensibility was determined by measuring the rate of the increase in stress just before it reached the above stress.

The results presented in this experiment showed the time courses of growth of first leaf, coleoptiles and root in rice seedlings at different concentrations of lead (Figs 1 - 3). The lengths of first leaf, coleoptiles and root were gradually increased with passing time (up to 5 days) but decreased with the increase of $\mathrm{Pb}$ concentrations. The reduction of lengths of first leaves and coleoptiles was not significant at any concentration of Pb (Figs 1 - 2) but that of root lengths of all days was found significant at the concentrations of $1-30 \mu \mathrm{M}$ Pb compared to control (Fig. 3).

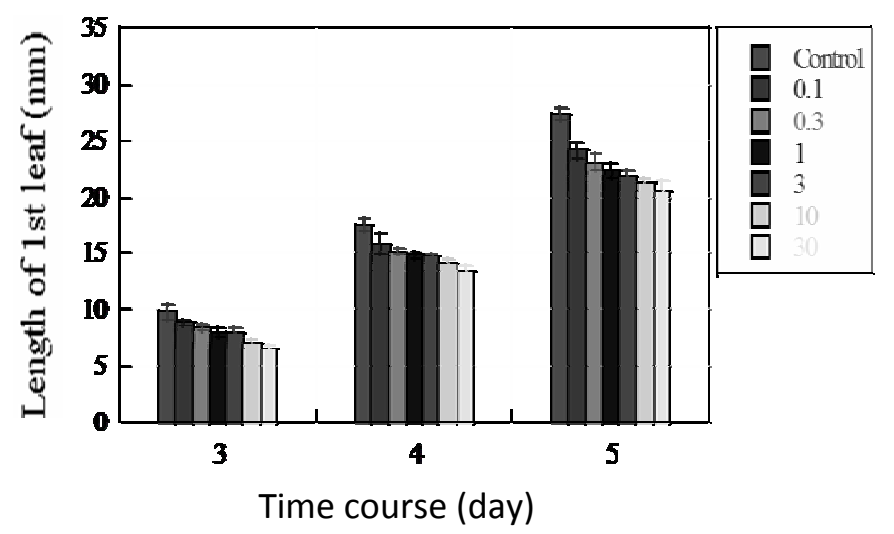

Fig. 1. Time courses of growth of first leaf in rice

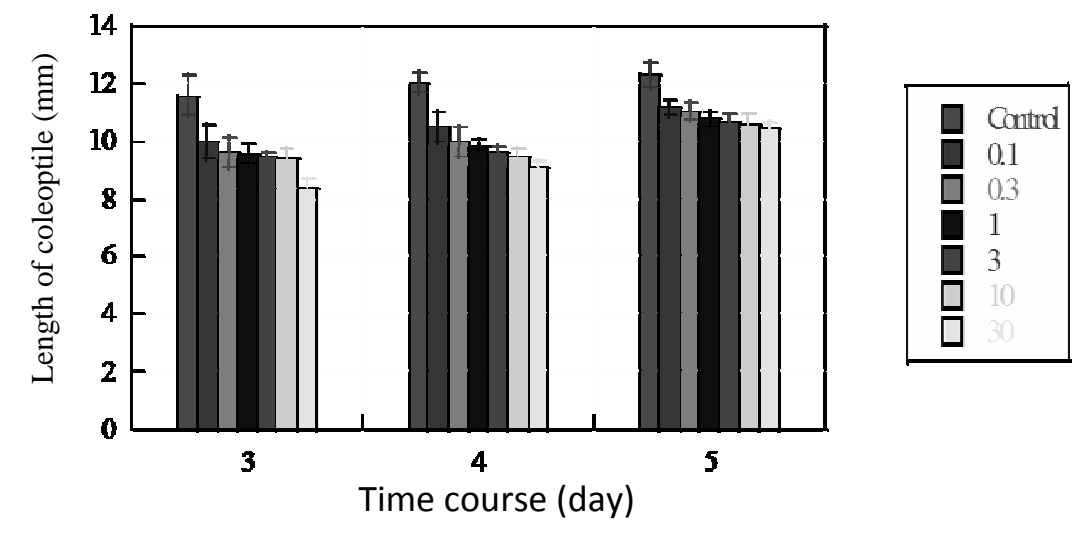

Fig. 2. Time courses of growth of coleoptiles in rice.

Findings obtained from the time courses of growth in rice seedlings showed that growth suppression by $\mathrm{Pb}$ was prominent in roots, but not clear in shoot organs, such as coleoptiles or first leaves, suggesting that roots are the primary target of $\mathrm{Pb}$ toxicity. $\mathrm{Pb}$ uptake studies in plants have demonstrated that roots have an ability to take up significant quantities of $\mathrm{Pb}$ whilst simultaneously greatly restricting its translocation to above ground parts (Lane and Martin 1977). Seregin and Ivanov (1997) pointed out that the limited transport of $\mathrm{Pb}$ from roots to other organs is 
due to the barrier of the root endodermis. This may be the reason for higher accumulation of $\mathrm{Pb}$ in roots than coleoptiles or first leaves and the accumulation of $\mathrm{Pb}$ is responsible for reduced growth of roots than coleoptiles or first leaves. The results in Fig. 4 showed that the length and fresh weight per root of rice seedlings were gradually decreased, although the fresh weight per unit length of root was slightly increased with the increase of $\mathrm{Pb}$ concentrations. However, the reduction of length and fresh weight of root was found significant at the concentrations of 1-10 $\mu \mathrm{M} \mathrm{Pb}$ (Fig. 4). In this context previous reports revealed that the inhibition of root growth under $\mathrm{Pb}$ toxicity was caused by the $\mathrm{Pb}$-induced inhibition of cell division and chromosome stickiness of root tips (Eun et al. 2000, Wierzbicka 1994).

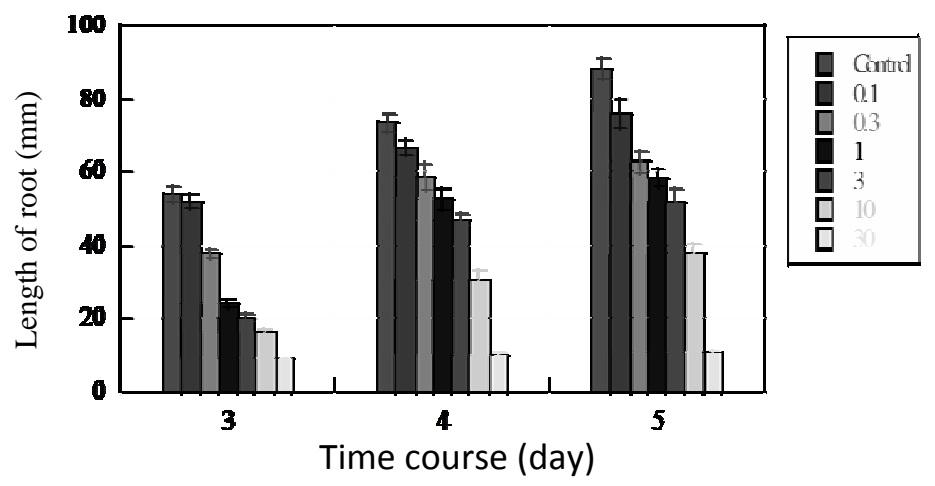

Fig. 3. Time courses of growth of root in rice
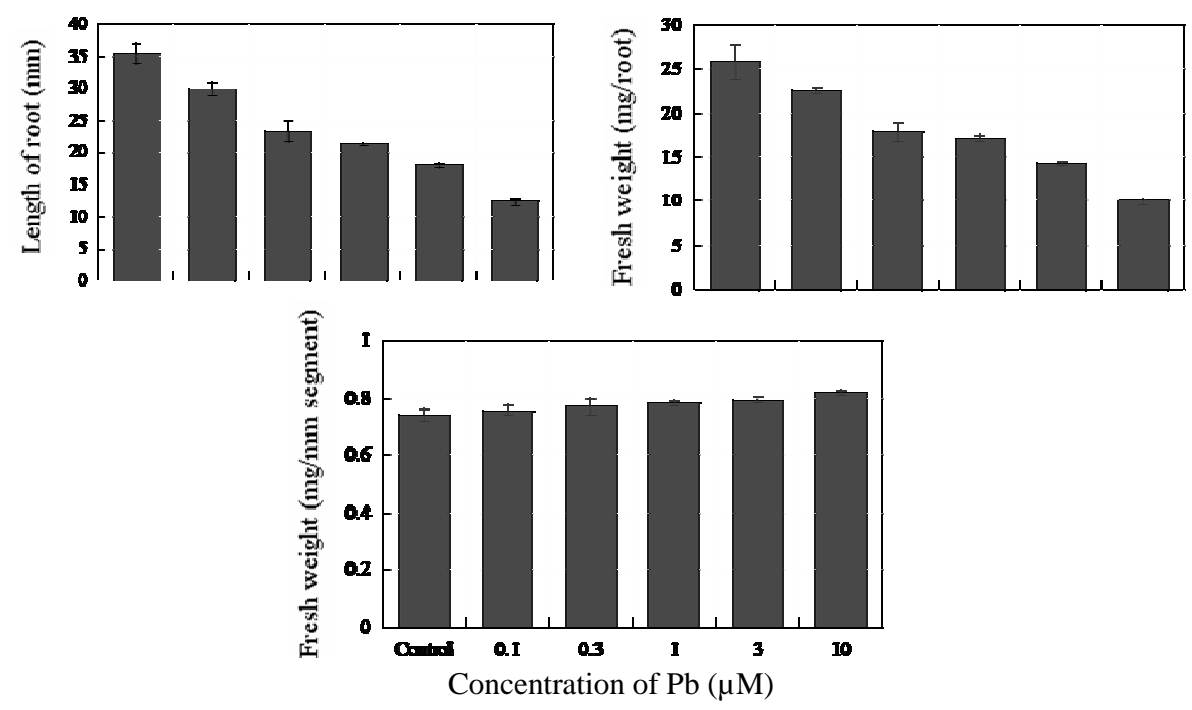

Fig. 4. Effect of lead on length and fresh weight of rice root grown for 3 days.

The analysis of the cell wall extensibility of root apical region indicated that cell wall extensibility was gradually decreased with increased concentration of $\mathrm{Pb}$ ions (Fig. 5). The cell wall extensibility was decreased greatly and significantly at the concentrations of $0.3-10 \mu \mathrm{M} \mathrm{Pb}-$ treated seedlings (Fig. 5). Moreover, the fresh weight per unit length of root was slightly increased with the increase of $\mathrm{Pb}$ concentrations (Fig. 4). These results suggest that $\mathrm{Pb}$ may influence the 
synthesis of cell wall polysaccharides, thereby decreasing the cell wall extensibility, resulting in growth suppression in rice roots.

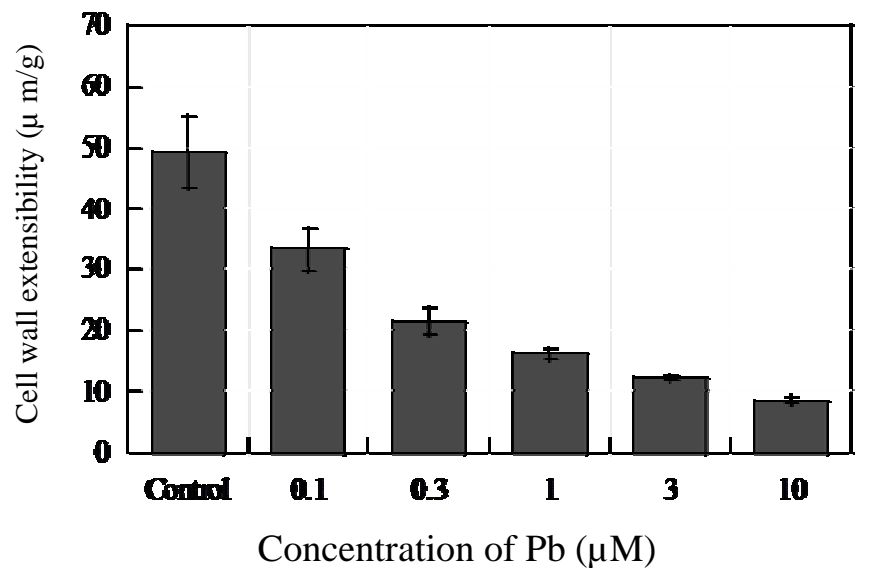

Fig. 5. Effect of lead on the cell wall extensibility of apical region of rice root grown for 3 days.

\section{Acknowledgements}

This research was conducted at Plant Physiology laboratory of Osaka City University by the support of Japan Student Services Organization-JASSO Follow up Research Fellowship program which is gratefully acknowledged with thanks.

\section{References}

Burton KW, Morgan E and Roig A 1984. The influence of heavy metals on the growth of sitka-spruce in South Wales forests. II green house experiments. Plant Soil. 78: 271-282.

Eun SO, Youn HS and Lee Y 2000. Lead disturbs microtubule organization in the root meristem of Zea mays. Physiol. Plant. 110: 357-365.

Hossain MT, Hossain F and Karim MA 2007. Effect of lead on germination, growth and chlorophyll contents in mungbean at early seedling stage. Bangladesh J. Life Sci. 19(1): 41-48.

Lane SD and Martin ES 1977. A histochemical investigation of lead uptake in Raphanus sativus. New Phytol. 79: 281-286.

Mishra A and Choudhari MA 1998. Amelioration of lead and mercury effects on germination and rice seedling growth by antioxidants. Biol. Plant. 41: 469-473.

Rudakova EV, Karakis KD and Sidorshina ET 1988. The role of plant cell walls in the uptake and accumulation of metal ions. Fiziol. Biochim. Kult. Rast. 20: 3-12.

Sharma P and Dubey RS 2005. Lead toxicity in plants. Braz. J. Plant Physiol. 17(1): 35-52.

Seregin IV and Ivaniov V B 1997. Histochemical investigation of cadmium and lead distribution in plants. Fiziol. Rast. 44: 915-921.

Wierzbicka M 1994. Resumption of mitotic activity in Allium cepa root tips during treatment with lead salts. Environ. Exp. Bot. 34: 173-180. 